\title{
Defining the envelope for the search for life in the Universe
}

\author{
Lynn J. Rothschild \\ Mail Stop 239-20, NASA Ames Research Center, Moffett Field, CA 94035-1000, USA \\ email: lynn.j.rothschild@nasa.gov
}

\begin{abstract}
The search for life in the universe relies on defining the limits for life and finding suitable conditions for its origin and evolution elsewhere. From the biological perspective, a conservative approach uses life on earth to set constraints on the environments in which life can live. Conditions for the origin of life, even on earth, cannot yet be defined with certainty. Thus, we will describe what is known about conditions for the origin of life and limits to life on earth as a template for life elsewhere, with a particular emphasis on such physical and chemical parameters as temperature, $\mathrm{pH}$, salinity, desiccation and radiation. But, other life forms could exist, thus extending the theoretical possibility for life elsewhere. Yet, this potential is not limitless, and so constraints for life in the universe will be suggested.
\end{abstract}

\section{Introduction}

To find something one has to know where to look. From Earth to the edge of the observable universe is about 46.5 billion light-years, so for the moment we must narrow the search considerably to where it is possible for life to reside, while staying within our technological bounds. Life is always likely to be based on organic carbon because carbon is the fourth most common element in the universe, its chemical versatility, the discovery of organic compounds elsewhere, and the fact that we are made of it (Rothschild 2009). Thus, as a first order organic compounds must be stable and function in order for life to exist, which provides a theoretic maximum envelope for life. Because Earth is only one place that life is known thus far, the minimum envelope is derived by assessing the environmental limits for life on Earth. But what a minimum envelope, as life swarms over Earth in many niches that until recently seemed uninhabitable.

\section{The extremes of life}

The extreme environments and examples of organisms that inhabit them are listed in Table 1. All of these environments at some point make it difficult for organic carbon to stay intact and/or for a solvent - such as water for Earth-based life - to stay liquid (see review in Rothschild 2009). Further, each environment can add other complexities. For example, at low temperatures membranes loose their fluidity and enzymatic reactions are slowed to the point that they cannot sustain life. Radiation and oxidative damage are of particular interest as they provide physical and chemical limits to life, but also act to mutate the genetic material. To this end, our lab has conducted experiments in high ultraviolet environments from the Bolivian Altiplano to Mount Everest, and by transporting biological samples to $33 \mathrm{~km}$ on high altitude balloons through Stanford's BioLaunch program. 


\begin{tabular}{|c|c|c|c|}
\hline Environment & Type & Definition & Example \\
\hline Temperature & $\begin{array}{l}\text { hyperthermophile } \\
\text { thermophile } \\
\text { mesophile } \\
\text { psychrophile }\end{array}$ & $\begin{array}{l}\text { growth }>80^{\circ} \mathrm{C} \\
\text { growth } 60-80^{\circ} \mathrm{C} \\
\text { growth } 15-60^{\circ} \mathrm{C} \\
\text { growth }<15^{\circ} \mathrm{C}\end{array}$ & $\begin{array}{l}\text { Pyrolobus fumarii- } 113^{\circ} \mathrm{C} \text { strain } 121 \\
\text { Homo sapiens } \\
\text { Psychrobacter, insects }\end{array}$ \\
\hline $\mathrm{pH}$ & $\begin{array}{l}\text { alkaliophile } \\
\text { acidophile }\end{array}$ & $\begin{array}{l}\mathrm{pH}>9 \\
\text { low } \mathrm{pH} \text { loving }\end{array}$ & $\begin{array}{l}\text { OF4 }(10.5) ; 12.8 ? \\
\text { Cyanidium, Ferroplasma }\end{array}$ \\
\hline Desiccation & xerophile & $\begin{array}{l}\text { cryptobiotic } \\
\text { anhydrobiotic }\end{array}$ & tardigrades \\
\hline Salinity & halophile & $2-5 \mathrm{M} \mathrm{NaCl}$ & Haloarcula, Dunaliella \\
\hline Radiation & & high radiation & Deinococcus radiodurans \\
\hline Oxygen & $\begin{array}{l}\text { anaerobe } \\
\text { miroaerophil } \\
\text { aerophile }\end{array}$ & $\begin{array}{l}\text { cannot tolerate } \mathrm{O}_{2} \\
\text { low levels of } \mathrm{O}_{2} \\
\text { mid to high } \mathrm{O}_{2}\end{array}$ & $\begin{array}{l}\text { Clostridium } \\
\text { Methanococcus jannaschii } \\
\text { Homo sapiens }\end{array}$ \\
\hline Pressure & $\begin{array}{l}\text { barophile/ } \\
\text { piezophile }\end{array}$ & $\begin{array}{l}\text { pressure/ } \\
\text { weight loving }\end{array}$ & $\begin{array}{l}\text { Shewanella viable at } 1600 \mathrm{MPa} \\
\text { tardigrades }\end{array}$ \\
\hline Vacuum & & tolerates vacuum & tardigrades, insects, microbes, seeds \\
\hline Gravity & hypo/hypergravity & $<1 \mathrm{~g} />1 \mathrm{~g}$ & none known \\
\hline Chemical & gasses, metals & $\begin{array}{l}\text { tolerates } \\
\text { high levels }\end{array}$ & $\begin{array}{l}\mathrm{CO}_{2}(\text { Cyandium cadarium }) ; \mathrm{Cu} / \mathrm{As} / \\
\mathrm{Cd} / \mathrm{Zn} \text { (Ferroplasma acidarmanus })\end{array}$ \\
\hline Electricity & & & electric eel \\
\hline
\end{tabular}

Table 1. Examples of extremophiles. Adapted from Rothschild \& Mancinelli (2001).

\section{Could it happen again?}

To assess if life could arise again and inhabit these niches, once again the biodiversity of life on Earth provides clues. When more than one organism has converged on a solution for an environmental extreme, it gives us more confidence that this evolutionary adaptation is not a one time event (Rothschild 2008). Multiple organisms have evolved to function at low and high temperature, low and high $\mathrm{pH}$ and so on. This suggests that there may be some universality - at least given the starting points of organic carbon and liquid water as a solvent - to the extreme environments for life.

\section{Where is the field heading?}

As we find more locations in our solar system and beyond that meet single variable constraints for life, attention must be paid to polyextremophiles, or organisms that can cope with multiple extreme parameters. Will this show that all possible niche space is occupied or that there are environmental combinations that, for some reason, cannot be occupied?

\section{References}

Rothschild, L. J. 2008, Phil. Trans. Royal Soc. B 363, 2787

Rothschild, L. J. 2009, in: C. Bertka (ed.), Exploring the Origin, Extent and Future of Life, (Cambridge: Cambridge University Press), p. 113

Rothschild, L. J. \& Mancinelli, R. L. 2001, Nature 409, 1092 